\title{
New Insights into Human Resource Management of Large Public Hospitals with Multi Campuses in China
}

\author{
Jialin Yang, Huafeng Cheng \\ South Campus, Renji Hospital, School of Medicine, Shanghai Jiao Tong University, Shanghai, China \\ Email: chenghuafeng@126.com
}

Received 10 July 2015; accepted 12 September 2015; published 15 September 2015

Copyright $@ 2015$ by authors and Scientific Research Publishing Inc.

This work is licensed under the Creative Commons Attribution International License (CC BY).

http://creativecommons.org/licenses/by/4.0/

c) (i) Open Access

\begin{abstract}
Human resource departments of large public hospitals in China deal with new challenges caused by multi-campus structure, such as increased labor demand, difficulty in cost management, lack of professional talents, restriction on employing way and etc. Delphi Method and Focus Group were used as the chief methods to analyze the problems. Countermeasures are researched as staffing optimization, performance management, forming Expert Center, establishing HRM Framework based on the positions among campus and restricting the human resource department. The researches break away from traditional human resource practices, develop new application for future trends, and adapt to the changes of business in the country's public hospital reform.
\end{abstract}

\section{Keywords}

Large Public Hospital, Multi Campuses, Human Resource Management Practices

\section{Background and Introduction}

Large public hospitals are the main body of China's health care system. From January to November in 2014, the medical service offered by public hospitals account for $89.9 \%$ of whole hospitals, further, the large public hospitals provide the main part among whole public hospitals [1]. Caused by the large population, the supply and demand of healthcare services in China is still unbalanced. As the ongoing medical reform has entered a crucial stage, over the past several years, Chinese central and local governments have established many new campuses of large public hospitals to increase healthcare services. By the end of 2013, there were 28 such hospitals in Shanghai which built multi campuses, among the whole 43 hospitals [2].

Under the current situation of medical talent shortage, multi campuses construction of large public hospitals is 
an effective way to optimize the high-quality medical resource distribution. But in actual operating process, these hospitals faced with new challenges caused by multi-campus structure, such as increased labor demand, difficulty in cost management, lack of professional talents, restriction on employing way and etc. Meanwhile, very few studies have examined the impact of HRM practices on operational performance measures [3].

\section{Methodology}

\subsection{Research Design}

The research strategy employed was a case study. South Campus of Renji Hospital was chosen as the typical and model case of the new-built hospital campus in China. Renji hospital affiliated to Shanghai Jiao Tong University School of Medicine was founded in 1844 as the second western medicine hospital in China. Currently, the hospital consists of four campuses and Shanghai Cancer Institute, known as a municipal tertiary hospital providing medical treatment, teaching and research. South Campus of Renji Hospital, as one of the key practical projects of “ $5+3+1$ " in Shanghai, opened in December, 2012. As a pilot project of the public hospital reform, Renji Hospital initiated actions to analyze the problems and researches the countermeasures, exploring on human resource management of multi-campus Hospital. Findings from this study gave an indication on the status of other tertiary hospitals in China.

\subsection{Study Methods}

The study methods were Delphi Method and Focus Group. The Delphi Method study population was senior staff consisting of presidents of hospital, council members and directors of departments. These cadres were selected because they fully understood the situation. Most importantly, they would take the results of study into practice.

Focus Group Study was used to explore the views and perceptions of the employees in the south campus of the hospital. Medical and nursing members of staff were randomly selected. Single stage stratified random sampling of the first-line medical workers were done. Each cadre of staff was regarded as a stratum. A probability proportional to size approach was used.

\subsection{Data Collection Methods}

Structured questionnaires were used to collect quantitative data from 20 Delphi experts. The gender spilt between these experts was $60 \%$ males and $40 \%$ females. With regard to their educational levels, the distribution was 55\% doctoral degree, 35\% master degree, 10\% bachelor degree. With regard to their managerial position, the distribution was $20 \%$ managers of superior administrative organizations, $50 \%$ leaders of hospitals, $30 \%$ directors of clinical departments. Structured questionnaires cited six dimensions from the previous researches: cross region, large scale, high personal mobility, difficulty in talent management during the rapid development period, internal coordination, business portfolio [4]. Each dimension was offered a choice of five point scale: very important, important, moderately important, of little importance, unimportant. Each of the five responses would have a numerical value ( 1 - 5 points) which would be used to quantitatively measure the attitude towards key problems caused by multi-campus structure.

The structured questionnaires were submitted to collect quantitative data. Through these data, the research emphasis was focus on specific issues. The semi-structured questionnaires were used to collect further information and improvement suggestions. Combined with the results of structured questionnaires, semi-structured questions followed were designed to get the rationalization proposals for countermeasure research.

- What were the key problems caused by multi-campus structure?

- Why did you think the above problems were more crucial?

- What were the underlying causes behind the problems?

- How could the general hospital deal with such problems?

- How could the new-built campus deal with such problems?

- If we take your suggestion, from which aspects can we examine the impact of related practices?

A question guide was used for 3 focus group discussions. Separate focus group discussions were done with 2 human resource practitioners, 2 clinical specialists and 2 first-line medical workers. Respondents were randomly selected from lists of doctors, nurses and other clinical workers. The information collected from focus group discussion contributed to analyze the problems from different perspectives. 


\subsection{Methods of Data Analysis}

Quantitative data was analyzed by using Statistical Package for Social Scientists (SPSS) 20.0. Data analysis was conducted through descriptive statistics analysis, including weighted statistic, variance analysis and frequency analysis. Qualitative data was recorded in hard copy form. Transcripts of qualitative data were analyzed throughout data collection to determine when data saturation was reached. Transcripts were reviewed to identify relevant and prominent themes, narratives and memorable quotes captured from focus group discussions and key informant interview. Themes coming out of transcripts were coded for easy interpretation.

\section{Findings}

\subsection{Cost Accounting and Controlling}

The main focus of almost all Delphi experts was the problem of cost accounting and controlling. The survey results are showed in the Table 1.

Similarly, according to group discussions, the new-built campuses shared culture and reputation resource with general hospital. The whole advantages in market competition have fully been shown. However, the scale expansion of multi-campus hospital increased administrative levels and widen administrative spans, bringing increased cost of administrative bureaucracy. Hence, both general hospital and the new-built campuses must think about how to display the groups scale advantage and the synergy effect.

Additional factor was the statistical data showed that the location-transfer of professionals within 3 months has reached 197 person-times. On the one hand, the personal expenditure of new-built campus need be accounted independently, which was troubled by the high personal mobility. On the other hand, human resources were necessary to be shared. Lack of relatively reasonable mode of accounting would inevitably restrain the demand and motivation of necessary personal exchange among campuses.

In addition, due to unavailability of a performance management system, focus group discussions showed that some doctors and nurses indicated that they were not recognized for a job well done and there were no sanctions for non-performers. It was to the benefit of neither the cost controlling, nor the manpower investment.

\subsection{Professional Talent Team Construction}

Delphi data showed that 15 respondents reported that they were not satisfied with the current condition of professional talent team construction. Group discussions with doctors showed that they were not satisfied with settlements, allowance policies and they often concerned the external opportunities.

Compared with the staffing ratio standard, there was a certain gap in both quantity and structure of physicians in the new-built campus.

From the external environment perspective, as the social capital was enlarging market of medicine service and the Chinese government has permitted doctors' multi-sited license, it was harder to attract and retain top medical talents. From the internal management perspective, the government budget rules restricted its payment of remunerations.

From the perspective of top medical talents' motivation, they paid attention to the pursuit of lifelong development. They preferred to increase their value through talent exchanges. Meanwhile, the scarcity of top talents and the growing demands for talents produced a variety of incentives and opportunities.

\begin{tabular}{|c|c|c|c|}
\hline Important degree & Related dimensions & Weighted sum & Main practical problems \\
\hline \multirow{3}{*}{ High } & High personal mobility & 96 & Cost accounting \\
\hline & Large scale & 83 & Cost controlling \\
\hline & $\begin{array}{l}\text { Difficulty in talent management } \\
\text { during the rapid development period }\end{array}$ & 81 & Professional talent team construction \\
\hline \multirow{2}{*}{ Average } & Internal coordination & 74 & Traditional adminstrative structure \\
\hline & Business portfolio & 67 & Discipline development \\
\hline Low & Cross region & 34 & - \\
\hline
\end{tabular}


From the perspective of overall hospital development strategy, campuses of the hospital must discuss a reasonable plan to attract and retain a number of professional talent teams, and guide the flow of talents among campuses within the hospital. The talent teams embodied the hospital brand. What's more, it was effective to deal with contradiction of talents supply and demand within the hospital.

\subsection{Factors That Affected the Restructuring of HRM Function}

Delphi data showed that almost half of the respondents indicated that they were frustrated with the traditional administrative structure. Focus group discussions showed that the restructuring of HRM function were affected by factors of reserves of medical talents, inner and outer environment, as well as conceptual design.

Until June 2014, there have been 383 medical professionals employed by south campus within 3 years. Only 8 of them were chief physicians and other 11 of them were experienced attending doctors. The time for reserve of talents was too short to build a mature team to support the operation of a new-built campus.

From the view of system theory, a system, as the hospital management system, contained regularly interacting or interrelating groups of activities. The organization restructuring was affected by the thought of managers, the current situation and external environment [5]. Especially as a public sector, recruitment and hiring were planned strictly by local government. When facing the adjustment of organizational structure, initiative and flexibility were limited.

If the administration departments were set independently in every campus, the cost of human resource management would multiply and to some degree, the management work couldn't be carried out intensively. In the process of management practices in the new-built campus, administrators should think outside the box and rely on advanced management thoughts to promote the restructuring of administration departments.

\section{Countermeasure Researches}

\subsection{Staffing Optimization and Performance Management}

In research of departments setting, countermeasures are implemented as flattening management system, merging and streamlining management functions. Totally five functional departments are set and number of administrative staff (including hospital leaders) is limited within 30. The daily works are assigned in the form of programs to promote the management innovation.

Based on international position evaluation system and improved to suit the hospital realities, management positions setting is innovative in the public hospital management practice, mainly reflected in the following aspects:

First, in view of the relative value between administration positions, close attention is paid to hospital operation and management efficiency. Through data mining, position evaluation can be done as quantitative research, to provide more objective data about the relative value of each administration position.

Second, in the process of setting the evaluative dimension, the value of position has been given greater prominence. Process-oriented indicators were selected, rather than seniority-oriented, in order to develop the full potential and improve the efficiency.

Public hospitals do not mean giving up the measure of the performance. Profit-making business models have provided the experiences of performance management. A new approach to the management of public sector, which is based on the principles of greater efficiency, responsibility and the need of quality, is often attributed to the new public management area [6].

As for administrative staff, the multidimensional performance management system was explored based on the results of position evaluation.

As for clinical departments, the modified version of balanced scorecard was used to give more relevance and functionality to strategic objectives and promote comprehensive medical quality management.

\subsection{Forming Expert Center and Establishing HRM Framework Based on the Positions among Campuses}

Human resources are the precious wealth of the whole hospital. So it's necessary to centralize all medical talents to support high-level medical technology development of every campus. Incentive policies are made to lead experts to form Expert Center, work across campuses. 
After forming Expert Center, the number of experts who open their specialist outpatient in the new-built campus has increased from 34 to 83 per month. The monthly data is shown in Table 2 below.

Table 3 shows the number of the experts from Expert Center who participate in the medical works in the new-built campus.

About 50 chief physicians are needed to support the new-built campus according to the provided beds. Before forming Expert Center, the monthly number of fixed experts was about 38. So the medical safety management encountered great risks. After forming Expert Center, there are average monthly 57 chief physicians participated in the medical works in the new-built campus. The medical quality has been greatly improved.

In addition, through using information technology as a tool, the Expert Center is not restricted by space and region. For example, experts of radiology department can offer comprehensive, state-of-the-art diagnostic radiology and image-guided services for every campus, while staying in general hospital, which forms a broader concept of Expert Center.

Kinds of contracts of staffs working in the new-built campus are shown in the following Table 4.

Employing way breaks through the traditional practices, diluting the concept of fixed-campus contract and exploring integrated management, to strengthen the team in the new-built campus step by step. By establishing human resource management framework based on the positions among campuses, the internal flexible employment was achieved.

To avoid the risk of medical quality caused by staff turnover, in the first level, application of attending physician teams as responsible units, ensures the quality control. In the second level, Human Resource System links with Hospital Information System, relating the personnel qualifications, positions and behaviors, to make the medical behaviors traceable.

\subsection{Restructuring the Human Resource Department}

In the human resource management practices, HR department has been divided into three sub-divisions: HR business partner, HR center of excellence and HR center of shared service, to replace traditional organization and management mode, as shown in Figure 1.

Table 2. Number of experts who open their specialist outpatient in the new-built campus.

\begin{tabular}{cccc}
\hline Time-span & Total experts & Fixed experts of new-built campus & Experts from expert center \\
\hline Jul. 2014 & 85 & 36 & 49 \\
Aug. 2014 & 83 & 28 & 55 \\
Sept. 2014 & 83 & 34 & 49 \\
Oct. 2014 & 84 & 35 & 49 \\
Nov. 2014 & 82 & 34 & 48 \\
Dec. 2014 & 82 & 37 & 45 \\
\hline
\end{tabular}

Table 3. Number of the experts from expert center working in the new-built campus.

\begin{tabular}{|c|c|c|c|}
\hline Time-span & Experts who open their outpatient & Experts who perform surgeries & Total experts from expert center \\
\hline Jul. 2014 & 49 & 13 & 57 \\
\hline Aug. 2014 & 55 & 10 & 55 \\
\hline Sept. 2014 & 49 & 14 & 58 \\
\hline Oct. 2014 & 49 & 16 & 56 \\
\hline Nov. 2014 & 48 & 20 & 61 \\
\hline Dec. 2014 & 45 & 18 & 53 \\
\hline
\end{tabular}




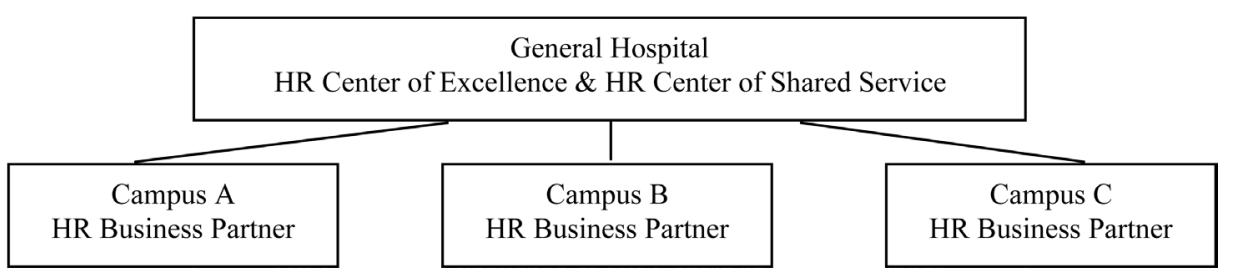

Figure 1. The organizational structure of restructured human resource department.

Table 4. Kinds of contracts of staffs working in the new-built campus.

\begin{tabular}{cccc}
\hline Kinds of Contract & First half of 2014 & Second half of 2014 & First half of 2015 \\
\hline General hospital & $44.5 \%$ & $36.1 \%$ & $32.9 \%$ \\
New-built campus & $27.2 \%$ & $33.1 \%$ & $34.3 \%$ \\
Talents dispatch & $28.3 \%$ & $30.8 \%$ & $32.8 \%$ \\
\hline
\end{tabular}

The concept of HR Business Partner is referred and developed from management experience of multinational companies [7]. Independent human resource department in the new-built campus was replaced by HR business partner model. HR business partner as an expatriate HR of general hospital works in the new-built campus. HR business partner mainly assists executives of the new-built campus in dealing with staff development and daily management works. The main works of HR business partner include two parts. The first part is to carry out the human resource management policies in accordance with general hospital. The second part is to provide unique solutions for the special strategic requirements of new-built campus. The practice reduces management cost and strengthens the flexibility and collaboration with the general hospital.

With the generating of HR business partner, HR center of excellence and HR center of shared service appear. These two characters are set in general hospital. HR center of excellence is made up of professionals in HR planning, recruitment, staff development, policy and law interpretation, compensation, performance, employee relations and other aspects. They mainly offer professional proposals and design effective solutions, serving for organizational reform. HR center of shared service deals with basic works centrally as social security, information maintenance, employee benefits and payroll for the whole hospital.

\section{Discussion}

In the first year of operation, the per capita outpatient and emergency patient number reached $92.5 \%$ of the average level of Shanghai 24 municipal hospitals, the per capita inpatient number reached 101.6\%, and per capita operation number reached $87.1 \%$. Human resource development was effective to ensure the new-built campus through the transition period smoothly.

Outpatient and emergency patient number increased 36\% year-on-year in first half of 2014, meanwhile, the inpatient number increased 60\% year-on-year. Medical business achieved leapfrog development. Therefore, forming Expert Center and establishing human resource management framework based on the positions among campuses adapt each campus and department to the development of the medical business and the changes of external demand flexibly and quickly.

As a result of Expert Center, specialist outpatient number increased almost 10\% quarterly from July 2013 to March 2015. At the same time, percentage of high-level surgeries increased from 33.7\% in first half of 2013 to $43.9 \%$ in second half of 2014. Both quality and quantity of the surgeries got improved. The comprehensive strength and brand of new-built campus have been promoted in a short period.

As a pilot project of the public hospital reform, Renji Hospital initiated actions to exploring the model of human resource management in large public hospital with multi campuses.

This project consists of the following five major components, namely staffing optimization, performance management, forming Expert Center, establishing HRM Framework based on the positions among campus and restricting the human resource department.

The innovative establishment of new management framework has created a smarter human resource management system solution. The experimental approach which aims at HRM reconstitution has been integrated in 
an overall system with HR business partner, HR center of excellence and HR center of shared service, so as to effectively utilize common resources.

Based on the problem analysis, the countermeasure researches break away from traditional human resource practices, develop new application for future trends, and adapt to the changes of business in the new reform.

Three main improvements of the practice are as following:

First, each campus should make the plans of discipline development in collaboration with others, which will give the opportunities for every department to take the initiative to adapt to the environmental changes, while the hospital can be more targeted to guide the subject development.

Second, combined with plans of discipline development, staff development strategies should be made to meet their intrinsic and extrinsic needs, including improving salaries levels, availability of resources, career pathways, housing and training, which is contributed to boost their working morale and self-esteem [8].

Finally, the training of medical talents has its unique mode. Now most researches on the hospital human resource management in China are just the mending on the existing framework. The Human Capital as an important issue should be taken in the trend of competition internationalization, hospital collectivization, the socialization of medical services and public hospital reform. Though these attempts have made ideal effect in human resource management of multi-campus hospitals, much more open innovations in both theory and practice are needed to promote hospital human capital development.

It is envisaged that after several years' efforts, each campus of Renji hospital will greatly improve their quality and efficiency of human resource management. In addition, these projects will also make remarkable progress in reforming the management system of large public hospitals and consequently become the bases for solving some major problems for the country's public hospital reform.

\section{References}

[1] National Health and Family Planning Commission of the People’s Republic of China. National Medical Service Data from January to November in 2014. http://www.nhfpc.gov.cn/zwgkzt/pwstj/list.shtml

[2] Jia, T.Y. and Yuan, H.Y. (2014) Culture Construction Strategies for the Hospitals with Multi Campuses. Hospital Administration Journal of Chinese People's Liberation Army, 21, 1090-1092.

[3] Aslan Sendogdu, A., Kocabacak, A. and Guven, S. (2013) The Relationship between Human Resource Management Practices and Organizational Commitment: A Field Study. Social and Behavioral Sciences, 818-827.

[4] Hu, H.P., Ren, G.W. and Su, R.K. (2011) Exploration on Collectivized Human Resource Management. Human Resource Management, 7, 134-136.

[5] Mikhaylov, F., Julia, K. and Eldar, S. (2014) Current Tendencies of the Development of Service of Human Resources Management. Social and Behavioral Sciences, 330-335.

[6] Raudeliuniene, J. and Meidute-Kavaliauskiene, I. (2014) Analysis of Factors Motivating Human Resources in Public Sector. Social and Behavioral Sciences, 719-726.

[7] McCracken, M. and Heaton, N. (2012) From Tucked away to Joined at the Hip: Understanding Evolving Relationships within the HRBP Model in a Regional Energy Company. Human Resource Management Journal, 22, 182-198. http://dx.doi.org/10.1111/j.1748-8583.2010.00150.x

[8] Chipeta, J.B. (2014) Factors That Affect Staff Morale in Tertiary Hospitals in Malawi: A Case Study of Kamuzu Central Hospital. Journal of Human Resource and Sustainability Studies, 2, 230-238. http://dx.doi.org/10.4236/jhrss.2014.24024 